\title{
AS TEORIAS DA RELATIVIDADE NO ENSINO BÁSICO: UMA REVISÃO DE LITERATURA PARA TRAÇAR O PERFIL DOS TRABALHOS PUBLICADOS NO BRASIL ENTRE 2000 E 2018
}

\author{
Wilton Souza Sampaio ${ }^{1}$, Antônio Nunes de Oliveira ${ }^{1}$, Marcos Cirineu Aguiar SiQueira $^{1}$ \\ ${ }^{1}$ Instituto Federal de Educação, Ciência e Tecnologia do Ceará \\ <wiltonsouzasampaio@gmail.com><nunes.vieira@ifce.edu.br><mcirineu@gmail.com>
}

DOI: https://doi.org/10.21439/conexoes.v13i4.1857

\begin{abstract}
Resumo. Em 2019 comemora-se o centenário do eclipse mais famoso de todos os tempos, aquele cujas observações comprovaram uma importante previsão da Teoria da Relatividade Geral, o desvio da luz pela gravidade, cujas notícias em jornais de todo o mundo fizeram de seu autor, Albert Einstein (1879-1955), uma celebridade mundial. Apesar do grande impacto histórico, social, cultural e tecnológico das Teorias da Relatividade (Relatividade Restrita e Relatividade Geral), assim como o interesse manifestado pelos estudantes por assuntos a elas relacionados, a aprendizagem de tópicos de Relatividade ainda não faz parte do cotidiano escolar na formação básica de muitos estudantes. Neste trabalho, apresentamos uma revisão de literatura envolvendo os principais estudos publicados no Brasil na área de pesquisa em Ensino de Física Moderna e Contemporânea, entre os anos 2000 e 2018, com vistas a justificar a presença de conteúdos de Relatividade no Ensino Básico e elencar as principais propostas elaboradas com o intuito de viabilizar a sua inserção. A pesquisa constatou que a quantidade de trabalhos desenvolvidos na área é muito pequena quando comparada à de Física Clássica e, até o próprio material didático costumeiramente utilizado nas escolas ainda dedica pouco espaço a esses temas, contudo, nos últimos anos, os pesquisadores têm trabalhado esse assunto com crescente interesse.
\end{abstract}

Palavras-chaves: Ensino de Relatividade. Ensino Básico. Revisão de Literatura.

\begin{abstract}
In 2019 is celebrated the centenary of the most famous eclipse of all times, the one whose observations proved an important prediction of the theory of general relativity, the deviation of light by gravity, whose news in newspapers from all over the world made its author, Albert Einstein (1879-1955), a world celebrity. Despite the great historical, social, cultural and technological impact of the theories of relativity (restricted relativity and general relativity), as well as the interest expressed by the students for related matters, the learning of topics of Relativity is not yet part of the routine of the school in the basic formation of many students. In this work, we present a literature review involving the main studies published in Brazil in the area of research in modern and contemporary physics teaching, between the years 2000 and 2018, with a view to justify the presence of relativity contents In basic education and to list the main proposals elaborated in order to enable their insertion. The research found that the amount of work developed in the area is very small when compared to that of classical physics, and even the didactic material used in schools still dedicates little space to these issues, however, in the last years, researchers have been working on this subject with increasing interest.
\end{abstract}

Keywords: Relativity teaching. Basic Education. Literature review.

\section{INTRODUÇÃO}

Há cerca de cem anos Albert Einstein (1879-1955) publicou a Teoria da Relatividade Restrita (TRR, 1905), responsável pela descrição dos movimentos na perspectiva de diferentes observadores inerciais, e a Teoria da Relatividade Geral (TRG, 1916), uma generalização da 
TRR para incluir referenciais não inerciais e a gravitação. Juntamente com a Física Quântica, as Teorias da Relatividade (TR) modificaram completamente o nosso modo de compreender o universo, no entanto, cabe destacar que a Física Clássica (FC) continua válida como uma aproximação dessas teorias para dimensões, velocidades e massas típicas à escala humana.

A princípio, a física einsteiniana não foi bem aceita pela comunidade científica, pois não é nada intuitiva quando comparada à FC, mesmo assim ela tem se sobressaído a todos os testes experimentais. Um dos testes bem sucedidos aconteceu no Brasil em maio de 1919, na cidade de Sobral, no Ceará, sendo de tamanha importância, que "de um dia para o outro, a imprensa se interessa pelo assunto, pela Relatividade Geral, e Einstein se tornara um homem público e o mais conhecido de todos os físicos" (EISENSTAEDT; FABRIS, 2004. p. 2). O teste consistia em medir a desvio angular da luz de uma estrela que se encontrava atrás do sol (na perspectiva de um observador na Terra), mas que, na ocasião do eclipse de 1919, segundo a previsão de Albert Einstein, mesmo a estrela estando atrás do Sol, um observador terrestre poderia vê-la devido à curvatura do próprio espaço, ocasionada pela presença do Sol.

Desde então, muitos outros testes igualmente bemsucedidos têm sido realizados. Mais recentemente, por exemplo, o Laser Interferometer Gravitational-Waves Observatory (LIGO) detectou as ondas gravitacionais previstas por Einstein há quase um século e, a primeira imagem de um buraco negro foi capturada pela colaboração do Telescópio do Horizonte de Eventos (The Event Horizon Telescope-EHT), sendo tais notícias amplamente divulgadas pela imprensa 1

Um terceiro exemplo, agora com respeito à TRR, diz respeito a eventos naturais como a dilatação temporal da vida média dos múons (partículas subatômicas que surgem a partir da colisão dos raios cósmicos com outras partículas que compõem a atmosfera terrestre). Os múons têm tempo de meia vida com duração de aproximadamente $2 \mu \mathrm{s}$, mas precisariam de pelo menos $30 \mu s$ para chegar à Terra, mesmo viajando à velocidade de mais de $0,99 c$, onde $c$ representa a velocidade da luz no vácuo $\approx 3 \cdot 10^{8} \mathrm{~m} / \mathrm{s}$. Quando consideramos a di-

\footnotetext{
${ }^{1}$ Einstein's Gravitational Waves 'Seen' From Black Holes Disponível em: https://www.bbc.com/news/science-environment35524440 . Acesso em: 26 de dez. de 2018;

Einstein's Gravitational Waves Found at Last. Disponível em https://www.nature.com/news/einstein-s-gravitational-waves-foundat-last-1.19361. Acesso em: 26 de dez. de 2018.

Primeira Imagem do Buraco Negro. Disponível em: http://www.sbfisica.org.br/v1/portalpion/index.php/noticias/86primeira-imagem-do-buraco-negro . Acesso em $07 \mathrm{de}$ dez. de 2019.
}

latação do tempo e/ou a contração do espaço, previstas pela TRR, vê-se que é possível a essas partículas chegarem à superfície da Terra e, de fato, "muitos [múons] sobrevivem até chegar à superfície da Terra" (TIPLER; LLEWELLYN, 2006, p. 28).

Uma grande parte da ciência e da tecnologia modernas só se tornou possível graças à evolução de nossos modelos e teorias físicas, que passaram a explicar e prever adequadamente uma gama maior de fenômenos. Tudo isso possibilitou vivermos em um mundo amplamente tecnológico onde, por exemplo, qualquer cidadão com um aparelho eletrônico específico de qualidade mediana (smartphone, computador, e etc.) tem acesso às informações de satélites e, por meio do GPS (Sistema de Posicionamento Global, em português), que faz correções relativísticas nos dados enviados, consegue saber, com precisão apreciável, a posição de objetos na superfície terrestre, o que é imprescindível para a navegação, a aviação e também nos deslocamentos diários de muitos motoristas.

O sistema GPS usa dados de satélites que mapeiam a Terra considerando a sua própria velocidade e os intervalos de tempo medidos por relógios localizados nos satélites e na Terra, obtendo assim uma coordenada espacial bem localizada no tempo. Dentro dos satélites há relógios atômicos muito precisos para fornecer a coordenada temporal, cujo desenvolvimento demandou conhecimento de Física Moderna. Por mais precisos que sejam, "os relógios são afetados de duas maneiras diferentes: sua velocidade relativa (Relatividade Restrita) e seu potencial gravitacional (Relatividade Geral)" (ZANOTTA; CAPELLETO; MATSUOKA, 2016. p. 5). Desta forma, os relógios podem adiantar ou atrasar por causa dos efeitos relativísticos e, para fazer as correções, é preciso considerar os aspectos relacionados às duas TR, de Albert Einstein.

Diante da importância, da fundamentação experimental e das aplicações tecnológicas das TR, neste trabalho fazemos um estudo bibliográfico buscando pesquisas que tenham como foco a inserção de tópicos de Relatividade no Ensino Básico e a sua divulgação para a população em geral. Esse mesmo estudo brota naturalmente a partir da inquietação quanto à presença aparentemente tímida das Teorias da Relatividade (TR) dentro das salas de aula do Ensino Básico (EB), conforme se evidencia em Oliveira et al. (2017), Paulo Neto, Oliveira e Siqueira (2019), em confronto direto com a sua crescente importância dentro do contexto científico e tecnológico do século XXI e visa elucidar sobre o estado da arte com relação às discussões acadêmicas feitas nesse sentido nos últimos anos. 
AS TEORIAS DA RELATIVIDADE NO ENSINO BÁSICO: UMA REVISÃO DE LITERATURA PARA TRAÇAR O PERFIL DOS TRABALHOS PUBLICADOS NO BRASIL ENTRE 2000 E 2018

\section{METODOLOGIA}

Considerando as TR como avanços importantes para a humanidade, este trabalho traz uma revisão bibliográfica das principais pesquisas publicadas no Brasil durante as duas últimas décadas, no que se refere à divulgação ou ao ensino de aspectos a elas relacionados. A intenção é contribuir destacando as principais propostas que podem ser aplicadas e/ou implementadas nas salas de aula durante a Educação Básica e, a partir dos trabalhos já existentes, sugerir estratégias que possam nortear novas propostas nesse sentido.

O principal recurso utilizado para reunir material foi a internet. Foram utilizadas técnicas de busca inteligente para construir uma amostra de maior tamanho possível e critérios subjetivos para filtrar dados e selecionar os textos representativos da população. O objetivo geral era reunir os textos mais expressivos produzidos pela comunidade acadêmica, seja no formato de artigos de periódicos, seja no formato de anais de eventos, seja como capítulos de livros. Particularmente buscou-se (i) categorizar os perfis dos trabalhos revisados de acordo com a problematização feita em cada um, (ii) identificar os principais veículos midiáticos que realizaram tais problematizações nos últimos anos, (iii) quantificar comparativamente as linhas temáticas dos trabalhos selecionados, separando-os em Física Clássica (FC), Teoria da Relatividade Restrita (TRR), Teoria da Relatividade Geral (TRG) e demais temas de Física Moderna e Contemporânea (FMC) e (iv) discutir os principais achados realizados dentro do período de estudo confrontando-os com as demandas da atualidade concernentes à inserção das TR no EB.

Para a produção deste trabalho foram percorridos os seguintes passos: a princípio, foi realizada uma pesquisa geral em busca de trabalhos com foco na divulgação ou ensino das TR, pesquisando por termos como: Relatividade Restrita, Relatividade Geral, teorias de Einstein, ensino de Relatividade e, em sequência, uma pesquisa mais direcionada, tomando como referências as revistas e anais de eventos em que foram publicados os trabalhos encontrados anteriormente, analisando todas as edições dos anos 2000 a 2018; depois da "garimpagem" de trabalhos, a próxima etapa adotada foi a leitura e análise das publicações elencadas com vistas ao traçado do perfil das publicações, de forma que chegouse à categorização disposta no Quadro 1. As categorias que seguem surgiram naturalmente durante o estudo da organicidade do conjunto de textos selecionados:

No Quadro 1 estão dispostas cinco categorias representativas da análise de aspectos considerados importantes nos trabalhos e do tipo de abordagem adotada pe-
Quadro 1: Categorização do Perfil dos trabalhos revisados.

\begin{tabular}{|c|c|}
\hline CATEGORIA & TEMA \\
\hline CATEGORIA 1 & Atenção dada ao assunto, no Brasil. \\
\hline CATEGORIA 2 & $\begin{array}{c}\text { Justificativa para a inserção de } \\
\text { tópicos de Relatividade no Ensino } \\
\text { Básico. }\end{array}$ \\
\hline CATEGORIA 3 & $\begin{array}{c}\text { O que pensam os professores e } \\
\text { alunos do EB sobre a inserção de } \\
\text { tópicos de Relatividade nessa etapa } \\
\text { de formação? }\end{array}$ \\
\hline CATEGORIA 4 & $\begin{array}{c}\text { Atenção dada à Relatividade em } \\
\text { livros didáticos destinados ao } \\
\text { Ensino Básico. }\end{array}$ \\
\hline CATEGORIA 5 & $\begin{array}{c}\text { Propostas para o ensino de } \\
\text { Relatividade. }\end{array}$ \\
\hline
\end{tabular}

los autores dos artigos consultados ao tratarem do tema Relatividade Restrita, ou Relatividade Geral, com vistas às inserções de tópicos a elas relacionados, no Ensino Básico (EB) ou mesmo à divulgação e popularização da ciência.

Além das revistas e dos anais de eventos foram considerados, dentro da nossa amostra, capítulos de livros cujos focos relacionavam-se com o tema de estudo e que foram publicados dentro do período em recorte, entretanto, por essa fonte de trabalhos não ter uma periodicidade fixa como têm as revistas e os eventos científicos, o estudo comparativo através de gráficos foi feito apenas para aquelas fontes com maior periodicidade e maior frequência de trabalhos relacionados. Com esse critério, deixamos fora da análise gráfica os livros e as revistas com publicações menos expressivas. Foram escolhidos relatórios científicos de naturezas distintas, na perspectiva de uma varredura completa de todas as produções acadêmicas relevantes no país referidas à inserção das teorias da relatividade no Ensino Médio, no sentido de se apreender todas as demandas educacionais reconhecidas no período considerado e de relacionar diretamente umas com as outras. Do ponto de vista prático, uma das metas do estudo feito inclui a detecção de lacunas e omissões da comunidade acadêmica com relação à presente conjuntura do Ensino de Física no nível básico da educação.

\section{RESULTADOS E DISCUSSÃO}

No Brasil, o foco das escolas de Ensino Fundamental e Médio parece estar na preparação dos alunos para a próxima etapa acadêmica, o Fundamental prepara para o Médio e o Médio prepara para o vestibular, sendo transmitida aos alunos a falsa ideia de que a ciência é 
AS TEORIAS DA RELATIVIDADE NO ENSINO BÁSICO: UMA REVISÃO DE LITERATURA PARA TRAÇAR O PERFIL DOS TRABALHOS PUBLICADOS NO BRASIL ENTRE 2000 E 2018

apenas um conjunto de pré-requisitos organizados em forma de disciplinas. Sob essa perspectiva, há pouco sentido em explorar os conceitos envolvidos nas TR, pois elas mesmas não alcançaram ainda a condição de exigência curricular.

Dentro deste contexto, os exames que se constituíram como a porta de entrada dos estudantes em nossas universidades, em especial, o Exame Nacional do Ensino Médio (ENEM) têm ditado o conteúdo programático de ciências na Educação Básica. Visando aprovar seus alunos nos vestibulares, as escolas têm se tornado verdadeiros centros de preparação para provas e, vêm se destacando na mídia, de acordo com seu nível de aprovação. Segundo Oliveira et al. (2017. p. 30), "Esse fato não deveria ocorrer, uma vez que a função social da escola é preparar o indivíduo para a vida em sociedade e torná-lo apto a assumir funções no mercado de trabalho". Neste contexto vem se formando uma visão deformada da verdadeira missão de uma escola, que por se constituir como núcleo de uma formação científica básica, deveria transmitir conteúdos e informações de forma significativa e formar um cidadão capaz de efetivar-se como tal diante de uma sociedade cada vez mais influenciada pela ciência e pela tecnologia.

\section{Análise da Categoria 1: Atenção Dada ao Assunto no Brasil}

Diante do exposto anteriormente, buscamos, mediante a análise dos trabalhos elencados, estabelecer um comparativo entre o ensino de Física Clássica (FC) e o de Física Moderna e Contemporânea (FMC). Tal estudo nos permitiu constatar que no Brasil há muito mais publicações tratando da primeira temática que da segunda. Paralelamente a isso, vê-se que o EB brasileiro dedica pouca atenção ao ensino de FMC (quando não o ignora por completo), especialmente no que se trata de TRR e TRG. Para ilustrar tais afirmações, foi construído o gráfico 1, a partir das principais fontes de pesquisa usadas na construção deste trabalho, sendo elas a Revista Brasileira de Ensino de Física (RBEF), o Caderno Brasileiro de Ensino de Física (CBEF) e o Simpósio Nacional de Ensino de Física (SNEF).

$\mathrm{Na}$ Figura 1. onde foram analisados 4.285 trabalhos, percebe-se que a maior concentração de textos com foco nas TR ou a elas relacionados, e que ocorrem dentro do período em estudo, se dá no SNEF, onde o volume de trabalhos relacionados ali publicados supera o dobro do número de trabalhos publicados com o mesmo foco no CBEF, o segundo com maior número detectado de trabalhos que possuem relação com a temática consi- derada. Observa-se, ainda que, das quatro modalidades consideradas no gráfico, a modalidade 'TRR ou TRG' é minoritária nos três periódicos.

Figura 1: Relação das quantidades de trabalhos separados por temática.

\section{Trabalhos publicados entre 2000 e 2018 \\ DFC DTRR OUTRG nDemais temas de FMC nOUTROS}

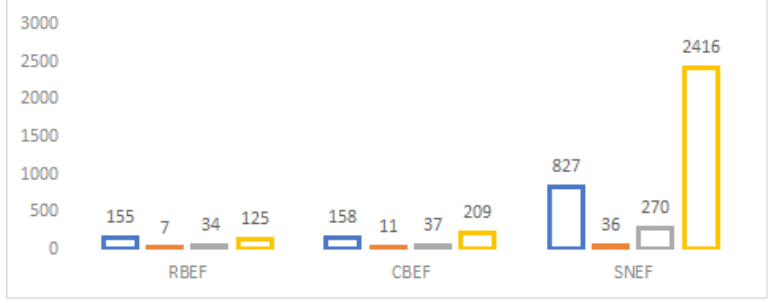

É importante saber que, nos casos dos RBEF e CBEF, a partir de certa época, os trabalhos começaram a ser disponibilizados por categorias, entre as quais algumas eram especificamente voltadas ao ensino de Física, e os trabalhos dessas categorias é que foram contabilizados. Ou seja, a Figura 1 não apresenta todo o montante de trabalhos disponibilizados pelos CBEF e $\mathrm{RBEF}$, mas apenas aqueles voltados diretamente ao ensino de Física.

Todas as atas consultadas do SNEF contêm exemplares da categoria TRR ou TRG, mas no caso da RBEF eles estão apenas nos anos de 2006, 2007, 2014 e 2015, e no CBEF nos anos de 2002, 2004 a 2007, 2009, 2010, 2016 e 2017; as sessões especiais de 2002 e 2004 do CBEF não foram contabilizadas, pois os trabalhos lá publicados vinham de edições anteriores da mesma revista, e a edição do SNEF de 2001 também não foi considerada por suas atas não estarem disponíveis no site da Sociedade Brasileira de Física; a categoria OUTROS é destinada a trabalhos que não se encaixam nas demais, como os que focam em matemática, astronomia, teorias de aprendizagem, meio ambiente, investigações sobre a educação, e etc.

Na Figura 2 é possível notar o crescimento no número de publicações envolvendo assuntos das TR, indicando um crescente interesse e envolvimento dos pesquisadores quanto a discutir e propor abordagens capazes de viabilizar a inserção desse tipo de conteúdo na Educação Básica. Apesar das altas e baixas ao longo dos anos, no geral percebe-se uma evolução tanto da quantidade de pesquisas publicadas quanto no número de pesquisadores envolvidos no estudo da temática, entre 2000 e 2018. Quanto aos picos comuns às três re- 
vistas, que aparecem nos períodos 2003-2005 e 20152018, fica sugerido que tais fatos se devem aos aniversários de fundação da TRR e da TRG, respectivamente.

Figura 2: Publicações envolvendo assuntos de TRR e TRG, com destaque ao SNEF, a RBEF e ao CBEF, entre 2000 e 2018.

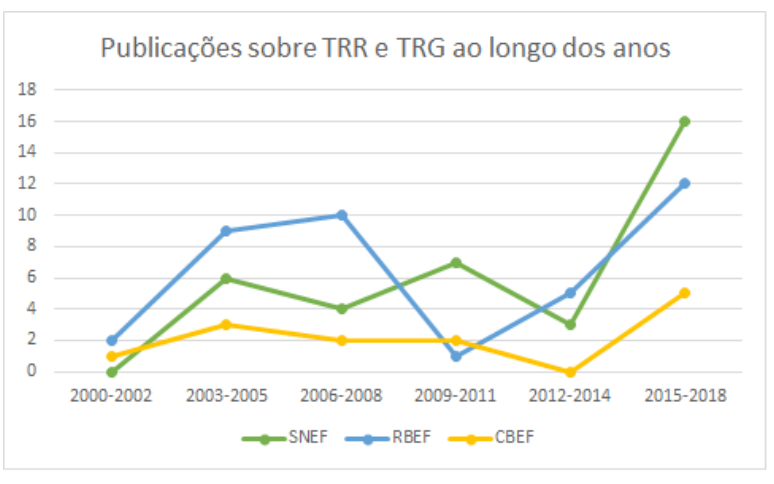

Apesar da oscilação nos números apresentados na Figura 2, é possível encontrar alguns bons trabalhos voltados ao ensino de FMC nos canais nacionais de divulgação científica. (GUERRA; BRAGA; REIS, 2007) mostram satisfação quanto a esse fato, afirmando que "o registro de trabalhos, mesmo que pontuais, é fundamental para que os autores do processo educacional tenham subsídios para reinventar suas práticas" (GUERRA; BRAGA; REIS, 2007, p. 8). Na verdade, talvez essa deficiência no ensino seja algo que motive os pesquisadores para investirem nessa linha de pesquisa, e de fato:

\section{Atualmente, as pesquisas que envolvem o ensino de Fí- sica Moderna e Contemporânea (FMC) no Ensino Médio já possuem um número bastante considerável de resulta- dos de forma que esta já possa ser considerada uma li- nha de pesquisa estabelecida dentro do Ensino de Física (SILVA; ARENGHI; LINO 2013 p. 2).}

O aumento considerável do número de publicações com foco no ensino ou divulgação da teoria da Relatividade, observado no cômputo geral, colabora com a implementação de novas práticas pedagógicas e com a superação de um ensino de Física centrado na FC.

\section{Análise da Categoria 2: Justificativa Para a Inserção de Tópicos de Relatividade no Ensino Básico.}

No que diz respeito a argumentos para a atualização curricular de modo a diversificar o currículo de Física com princípios e leis referentes à FMC e às suas aplicações tecnológicas, Silva, Arenghi e Lino (2013) justificam dizendo que a FC é limitada, sendo imprescindível ensinar no EB a Física capaz de abrir novas fronteiras e quebrar os antigos paradigmas. Segundo (GUERRA; BRAGA; REIS, 2007), os alunos devem ser levados a refletir sobre os limites e as possibilidades da ciência, mas isso só será possível, na disciplina de Física, se eles tiverem conhecimento das teorias de fronteira na área. Para (FERREIRA; SILVA, 2007):

\section{[...] se consideramos que é importante para o estudante a compreensão da evolução do pensamento científico, desde suas motivações até a elaboração de uma nova teo- ria, a transição da gravitação newtoniana até a sua gene- ralização através da TRG fornece um excelente exemplo, por sua completeza e elegância (FERREIRA; SILVA 2007 p. 1)}

De fato, levar os alunos a compreenderem como se dá o desenvolvimento da ciência é indiscutivelmente importante. Há muitos mitos populares direcionados à ciência que precisam ser desmistificados, tais como: cientistas não são normais, são pessoas frias e que não se divertem; as descobertas acontecem da noite para o dia (como na famosa estória em que Arquimedes teria gritado "Eureca" ao fazer uma descoberta repentina); cada descoberta científica é feita apenas por um cientista genial. Essas percepções errôneas podem ser evitadas quando a escola possibilita aos educandos o conhecimento básico acerca do processo histórico de construção da ciência.

Apesar da importância por eles dada à questão histórica, a ênfase no trabalho de Ferreira e Silva (2007) é na apresentação de tópicos da TRG, argumentando que o ensino de tais conteúdos no nível médio "é de fundamental importância para se entender a estrutura do universo que nos cerca e de inúmeros fenômenos nele existentes" (FERREIRA; SILVA, 2007, p. 1). Estar ciente de como o universo funciona é importante para o desenvolvimento da criticidade dos alunos, pois, segundo o trabalho citado, o ensino de TRG (na verdade da FMC como um todo) possibilita uma compreensão mais precisa do mundo físico.

\section{Análise da Categoria 3: O Que Pensam os Professo- res e Alunos do EB Sobre a Inserção de Tópicos de Relatividade Nessa Etapa de Formação?}

Depois de consultar alguns trabalhos, três se mostraram especialmente importantes para o propósito desta seção: Oliveira e Almeida (2013), Monteiro, Nardi e Bastos Filho (2009), Castro et al. (2003). Apesar de apenas um dos trabalhos tratar especificamente das teorias einsteinianas - pois os demais são mais abrangentes, ao falarem de FMC - podemos usar todos para de- 
AS TEORIAS DA RELATIVIDADE NO ENSINO BÁSICO: UMA REVISÃO DE LITERATURA PARA TRAÇAR O PERFIL DOS TRABALHOS PUBLICADOS NO BRASIL ENTRE 2000 E 2018

linear a opinião dos professores, visto que tanto a TRR quanto a TRG estão contidas dentro da FMC.

A pesquisa de Oliveira e Almeida (2013), realizada com 9 professores de Ensino Médio, sendo 3 da rede pública de ensino e 6 da particular, constatou que “ $100 \%$ deles acham necessário que conteúdos de Física Moderna sejam ensinados no ensino médio, no entanto, dos 9, apenas 1 se sente totalmente preparado para efetuar essa abordagem" (OLIVEIRA; ALMEIDA, 2013 p. 111). Ao responder o questionário elaborado pelos pesquisadores, um dos professores dessa mesma pesquisa afirma que "além de achar viável, acha necessário" o ensino de Física Moderna no Ensino Médio e justifica a sua fala usando os avanços tecnológicos e científicos dos últimos anos como argumento principal.

Ao entrevistarem 5 professores licenciados em Física e que lecionavam há pelo menos três anos no Ensino Médio, Monteiro, Nardi e Bastos Filho (2009) verificaram que todos eles consideram relevante a presença de FMC no EB, mas não trabalham esse tipo de conteúdo com seus alunos de nível médio. Um dos professores entrevistados afirma que "o tempo não é suficiente nem pra trabalhar a Física Clássica [...] e com as dificuldades dos alunos, a gente não consegue avançar muito, aí não dá pra terminar a Física Clássica" (MONTEIRO; NARDI; Bastos Filho, 2009, p. 150). A fala destacada anteriormente reflete a "preferência dos professores" por ministrar conteúdos de FC, deixando os de FMC para os casos em que o tempo seja favorável.

Cabe destacar que a exclusão de conteúdos de FMC no EB vem sendo cada vez mais motivada pelos exames de vestibulares, os quais, em grande parte, negligenciam alguns dos avanços científicos alcançadas nas últimas décadas.

Com um grupo maior, de 31 professores, Castro et al. (2003) realiza sua pesquisa também em escolas públicas e privadas, só que no estado de Minas Gerais, eles afirmam que quando questionados sobre a importância da Física Moderna na educação básica, apenas 27 professores responderam, e desses, $93 \%$ consideraram importante ensinar Física Moderna no Ensino Médio. Aqueles que disseram não considerar importante, apresentaram argumentos muito semelhantes aos relatados no trabalho anteriormente citado: "a carga horária disponível não comporta, e também devido ao baixo nível de compreensão da maioria dos alunos" (CASTRO et al. 2003, p. 6). Isso não justifica a declaração deles, mas apenas indica que eles priorizam os conteúdos tradicionais no trabalho cotidiano.

Apesar do interesse de que se ensine FMC no Ensino Médio, quando questionados sobre se eles tinham tempo para trabalhar esses conteúdos, os resultados foram:

$56 \%$ dos professores disseram não encontrar tempo e $19 \%$ afirmaram que sim. Os demais os professores (25\%) deram respostas como: "Tento encaixar alguns tópicos dentro do conteúdo tradicional."; "Somente trabalhando os temas em forma de comunicações."; e "Só para pequenos comentários quando solicitados ou para complementar alguma colocação.”, as quais consideramos respostas superficiais (CASTRO et al. 2003 p. 6).

Apesar dos conteúdos de TRR e TRG não aparecerem com grande frequência no EB, percebe-se, a partir da análise dessas publicações, que os professores consideram relevante, importante e até mesmo necessário, o ensino de FMC - e por consequência, de TRR e TRG - no EB.

\section{Análise da categoria 4: Atenção dada à Relatividade em livros didáticos destinados ao Ensino Básico.}

Mesmo diante desses argumentos destacando a importância do ensino de FMC para alunos do EB, os sistemas de ensino - nesse caso, especificamente os produtores de livros didáticos - ainda não dedicam muito espaço à TRG e à TRR. Em seu trabalho, Bezerra Junior e Groch (2009) investigam o quanto de espaço é dedicado à FMC em alguns livros didáticos brasileiros, e os dados são os apresentados no Quadro 2

As informações do Quadro 2 estão em concordância com as da Figura 1, sendo mais uma vez enfatizado que a FMC recebe bem menos atenção do que a FC no ensino de Física. Observando os dados dessa tabela, vemos que um percentual muito pequeno dos textos dos livros é dedicado à FMC, e consequentemente é ainda menor o espaço dedicado às TRR e TRG. Levando em conta que os livros analisados são de boa qualidade, no que se trata dos conteúdos apresentados, é de se esperar que livros de menor qualidade, geralmente usados no EB, dediquem ainda menos atenção a esse assunto. Considerando ainda que, em muitos casos, os professores nem chegam a ensinar os conteúdos finais do livro (TRR e TRG costumam ser posto no final dos livros), é notável que a grande maioria dos alunos do Ensino Médio (EM) nunca chegam a estudar TRR e TRG na escola.

Além de quanto espaço é dado aos conteúdos nos livros, a forma como os textos são distribuídos também determina o quão eficientes e úteis eles serão durante o processo de ensino. Dominguini (2012) analisa os livros didáticos dos autores já mencionados, incluídas 
AS TEORIAS DA RELATIVIDADE NO ENSINO BÁSICO: UMA REVISÃO DE LITERATURA PARA TRAÇAR O PERFIL DOS TRABALHOS PUBLICADOS NO BRASIL ENTRE 2000 E 2018

Quadro 2: Percentuais dos conteúdos de FMC em livros didáticos de Física do EB.

\begin{tabular}{|c|c|}
\hline OBRAS & DADOS CATALOGADOS \\
\hline A & $\begin{array}{c}\text { "[....] apresenta em apenas } 1,48 \% \text { de seu conteúdo a FMC, e apenas } 0,42 \% \text { para o estudo de } \\
\text { Relatividade Geral". }\end{array}$ \\
\hline B & “[...] a quantidade de conteúdos de FMC é de $6,77 \%$, sendo que RR e RG correspondem a 2,33\%”. \\
\hline $\mathrm{C}$ & "[...] há $1,9 \%$ de conteúdos de FMC, especificamente de RR e RG, 1,08\%". \\
\hline $\mathrm{D}$ & $\begin{array}{c}\text { “[...] contém apenas } 2,04 \% \text { de FMC e } 0,56 \% \text { de TRR, não faz abordagem de TRG, } \\
\text { tampouco apresenta atividades". }\end{array}$ \\
\hline $\mathrm{E}$ & $\begin{array}{c}\text { “[...] A FMC representa } 1,42 \% \text { do total dos três volumes, no qual foi computada também } \\
\text { uma lista de exercícios na secção 'questões de vestibular'. A obra não trata de maneira } \\
\text { específica a TRR e TRG”. }\end{array}$ \\
\hline $\mathrm{F}$ & $\begin{array}{c}\text { "[...] apresenta uma maior valorização quantitativa da FMC entre os livros didáticos } \\
\text { avaliados, } 11,47 \% \text { e especificamente de Relatividades: } 3,26 \% " .\end{array}$ \\
\hline
\end{tabular}

Fonte: (Bezerra Junior; GROCH, 2009)

outras duas obras não referidas até então. O autor constata que todos os livros didáticos do Programa Nacional do Livro Didático para o Ensino Médio (PNLEM) trazem em suas páginas conteúdos de FMC, “seja em forma de capítulo, ou unidade, ou textos dispersos ao longo da obra" (DOMINGUINI, 2012, p. 5) e, dentre os que foram analisados, com exceção da obra A, "todos os livros que apresentam o conteúdo de Física Moderna como capítulo específico, esse se localiza no final dos livros de volume único ou no final do último livro das coleções seriadas" (DOMINGUINI, 2012, p. 5).

Oliveira e Almeida (2013) questionam o fato desses conteúdos estarem situados apenas no último capítulo do último volume dedicado a abordagem de Física no terceiro ano do EB, segundo os autores é preciso e urgente que sejam pensadas propostas de abordagens sequenciadas dos conteúdos de FMC, em paralelo ao de FC.

\section{Análise da categoria 5: Propostas para o ensino de Relatividade.}

Os trabalhos analisados nesta seção abordam as TRR e TRG de forma experimental, históricofilosoficamente, ou apresentam sequências didáticas próprias para o EB. Visto que esses assuntos são considerados um tanto complicados, faz-se necessário que abordagens adequadas sejam desenvolvidas, de modo que o ensino seja facilitado. Como afirmam Medeiros e Medeiros (2005, p. 7), “[...] a ciência não precisa ser maçante. Ela pode ser realmente divertida! Crianças curiosas, ou que tenham suas curiosidades despertadas, poderão achar muito divertido lidar com brinquedos ao mesmo tempo em que aprendem como eles funcionam".
Em sua pesquisa, Medeiros e Medeiros (2005) propõem o uso de brinquedos 1 científicos que ilustram o Princípio da Equivalência, apresentando uma forma alternativa de divulgar a ciência de maneira mais lúdica. Sugerem que, através do uso de brinquedos, é possível levar às pessoas - de crianças a adultos - o conhecimento dos fenômenos físicos, sem assustar ou entediar ninguém com longas explicações teóricas. Claro que não há o propósito de desvalorizar a teoria, mas de ressaltar a importância da demonstração dos fenômenos físicos para a sua melhor compreensão.

Apesar da escassez de propostas desse tipo, Oliveira e Gomes (2016) apresentam uma proposta que também pode levar os alunos a uma aprendizagem significativa: o uso do teatro. Assim como os brinquedos já mencionados, o teatro envolve as pessoas de modo que a teoria ganha um significado mais marcante, isto ocorre tanto quando os alunos encenam como quando veem as cenas representando o processo de construção das teorias einsteinianas.

Os Parâmetros Curriculares Nacionais para o Ensino Médio (PCN+) chamam a atenção para o fato de que a disciplina de Física geralmente tem sido trabalhada simplesmente com resolução de problemas e abordada através da linguagem matemática, todavia não sendo esses instrumentos suficientes para levar os alunos a terem uma compreensão satisfatória das ideias físicas, então:

\footnotetext{
[...] surge a necessidade de inovar as práticas, buscando novas metodologias e estratégias que despertem no aluno competências específicas em Física, levando-o a interagir com competências de outras áreas de forma a se apropriar de um aprendizado mais amplo e interdisciplinar. Além de instigá-lo a pensar a Física de outras maneiras, procurando mantê-lo interessado na disciplina (OLIVEIRA; GOMES 2016 p. 3).
} 
Essas novas práticas, metodologias e estratégias, incluem a "linguagem corporal e artística" (BRASIL, 2002, p. 84), sugeridas pelos $\mathrm{PCN}+$ e presentes no teatro. A ação interdisciplinar envolvendo as disciplinas de Física, Arte e História, permite contextualizar os conteúdos e esclarecer aspectos relevantes do desenvolvimento científico, situando-o na história.

Além dos métodos citados, é muito importante a existência de textos didáticos que sirvam de material de apoio para professores e alunos do Ensino Médio. É claro que os livros didáticos já devem cumprir esse papel, porém a publicação de trabalhos nesse sentido pode ser de grande ajuda aos professores que querem se aprofundar mais no assunto, e saber quais caminhos podem ser seguidos para melhor ensinar. Então, o trabalho de Ferreira e Silva (2007) não pode deixar de ser mencionado aqui como um excelente exemplo desse tipo de publicação.

\section{[...] propomos um texto simples sobre a TRG que ser- visse de apoio didático para professores e estudantes do nível médio, já que existe no Brasil uma enorme carência de textos sobre tal tópico, apesar de algumas iniciativas através da introdução de seções ou capítulos sobre o as- sunto em textos voltados para este nível de escolaridade (FERREIRA; SILVA 2007, p. 9)}

O artigo citado acima segue uma sequência didática bem interessante, conduzindo os alunos à assimilação das ideias qualitativas da TRG. Primeiramente falando do Princípio da Equivalência, os autores mostram através de um experimento mental como o espaço-tempo é curvado pela matéria, em seguida - usando um pouco de geometria não euclidiana - é mostrado como a matéria e energia se comportam nesse espaço-tempo curvo. Tudo é tratado de forma bastante simples, seguindo raciocínios até intuitivos, e nas palavras dos autores: "espera-se que este texto auxilie o professor de Ensino Médio a estabelecer com seus estudantes as bases da TRG, permitindo que estes compreendam as diferenças de construção das duas teorias ${ }^{2}$, bem como seus limites de validade" (FERREIRA; SILVA, 2007, p. 9).

\section{CONSIDERAÇÕES FINAIS}

Dentre as principais publicações veiculadas no Brasil na área do Ensino de FMC entre os anos de 2000 e 2018, sobressaíram-se quantitativamente a RBEF, o CBEF e o SNEF, com destaque para o último, no que se refere à veiculação de trabalhos direcionados especificamente ao ensino de Física. A partir do levantamento

\footnotetext{
${ }^{2}$ Teoria clássica e teoria einsteiniana.
}

feito, as publicações foram subdivididas em quatro modalidades, dentre as quais a modalidade "TRR ou TRG" ocupou posição minoritária. Contudo - não levando em conta qual das modalidades mais cresceu, pois isso não foi considerado durante a pesquisa - no cômputo geral, a referida modalidade experimentou um notável crescimento dentro do período estudado.

Um grande número de trabalhos tem sido publicado nos últimos anos problematizando a inserção das TR no Ensino Básico. De um modo geral, os autores realçam as grandes limitações da FC na descrição do comportamento do universo e da realidade tecnológica de nosso tempo, e muitos deles, inquirindo professores e alunos, apontam para índices que beiram a totalidade nas taxas de aprovação da FMC, de um modo geral. Apesar disso, o levantamento constatou que a presença das TRR e TRG dentro dos livros didáticos ainda é muito tímida (menos de $3,5 \%$ do conteúdo total), conforme Bezerra Junior e Groch (2009), e sempre concentrada no final do último livro.

É comum professores justificarem a ausência de conteúdos de FMC em sala de aula alegando falta de capacitação de sua parte, mas alguns trabalhos citados aqui (categoria 5) foram elaborados com o intuito de contribuir para a superação desse inconveniente. Desde o uso de experimentos de baixo custo, interdisciplinaridade entre Física, Arte e História, até materiais didáticos em linguagem simplificada, há boas propostas de ensino de fácil aplicação aos professores e alunos do $\mathrm{EB}$, as quais estiveram em constante desenvolvimento entre os anos de 2000 a 2018.

Visto que as TRR e TRG fornecem um modelo mais atualizado do universo, é muito importante dar continuidade ao desenvolvimento de trabalhos sobre o ensino desses conteúdos, de modo que a FMC esteja cada vez mais presente na Educação Básica. Mais que isso, é importante garantir que todas as publicações apresentadas possam tornar os professores conscientes da importância de ensinar TRR e TRG, fornecendo-lhes informações e indicando-lhes os materiais de apoio disponíveis no mercado.

Trabalhos futuros poderão propor alternativas para abordagem de tópicos específicos das TR, concomitantemente a determinados assuntos da FC. Uma alternativa, por exemplo, seria abordar o uso do cinto de segurança do ponto de vista de um observador interno ao veículo e justificá-lo usando como argumento o princípio de Equivalência da Relatividade Geral.

\section{REFERÊNCIAS}

Bezerra Junior, A. G.; GROCH, T. M. O ensino 
AS TEORIAS DA RELATIVIDADE NO ENSINO BÁSICO: UMA REVISÃO DE LITERATURA PARA TRAÇAR O PERFIL DOS TRABALHOS PUBLICADOS NO BRASIL ENTRE 2000 E 2018

de relatividade restrita e geral nos livros didáticos do pnlem 2009. In: SIMPÓSIO NACIONAL DE ENSINO DE FÍSICA. Espírito Santo: Atas do XVIII SNEF, 2009. v. 18

BRASIL. Ciências da natureza, matemática e suas tecnologias./ Secretaria da Educação Média e Tecnológica. PCN + Ensino Médio: Orientações Educacionais complementares aos Parâmetros Curriculares Nacionais. Brasília, 2002.

CASTRO, R. A.; CORRÊA, F; JOÃO, A.; GONçALVES, H. A. A inserção da física moderna no ensino médio. In: SIMPÓSIO NACIONAL DE ENSINO DE FÍSICA. Curitiba: Atas do XV SNEF, 2003. v. 15 , p. $1780-1789$.

DOMINGUINI, L. Física moderna no ensino médio: com a palavra os autores dos livros didáticos do pnlem. Revista Brasileira de Ensino de Física, v. 34, n. 2, p. 2502, 2012.

EISENSTAEDT, J.; FABRIS, J. C. Amoroso costa e o primeiro livro brasileiro sobre a relatividade geral. Revista Brasileira de Ensino de Física, SciELO Brasil, v. 26, n. 2, p. 185 - 192, 2004.

FERREIRA, R. C.; SILVA, M. F. A. Uma proposta para a introdução da relatividade geral no ensino médio. In: SIMPÓSIO NACIONAL DE ENSINO DE FÍSICA. São Luis: Atas do XVII SNEF, 2007. v. 17.

GUERRA, A.; BRAGA, M.; REIS, J. C. Teoria da relatividade restrita e geral no programa de mecânica do ensino médio: uma possível abordagem. Revista Brasileira de Ensino de Física, v. 29, n. 4, p. 575-583, 2007.

MEDEIROS, A.; MEDEIROS, C. F. de. Einstein, a física dos brinquedos e o princípio da equivalência. Caderno Brasileiro de Ensino de Física, Universidade Federal de Santa Catarina (UFSC), v. 22, n. 3, p. 299-315, 2005.

MONTEIRO, M. A.; NARDI, R.; Bastos Filho, J. B. Dificuldades dos professores em introduzir a física moderna no ensino médio: a necessidade de superação da racionalidade técnica nos processos formativos. In: NARDI, R. (Ed.). Ensino de ciências e matemática, I: temas sobre a formação de professores. São Paulo, 2009.

OLIVEIRA, A. N.; ALMEIDA, C. A. S. Ensino

de relatividade especial no ensino médio: uma abordagem progressiva. In: LIMA, I. B. (Ed.). Didática, Educação Ambiental e Ensino de Ciências e Matemática: múltiplos olhares, II: didática e ensino de ciências e matemática. Fortaleza, 2013.

OLIVEIRA, A. N.; BEZERRA, I. A.; FRAGA, W. B. de; SIQUEIRA, M. C. A. Ensino da teoria da relatividade em sobral (ce): uma pesquisa com professores e alunos egressos do ensino médio. ScientiaTec: Revista de Educação, Ciência e Tecnologia do IFRS, v. 4, n. 3, p. 18 - 36, 2017.

OLIVEIRA, L. M.; GOMES, M. L. Einstein e a relatividade entram em cena: diálogos sobre o teatro na escola e um ensino de física criativo. Caderno Brasileiro de Ensino de Física, Universidade Federal de Santa Catarina (UFSC), v. 33, n. 3, p. 943-961, 2016.

Paulo Neto, J. G.; OLIVEIRA, A. N. de; SIQUEIRA, M. C. A. Ensino de física moderna e contemporânea no ensino médio: o que pensam os envolvidos? ScientiaTec: Revista de Educação, Ciência e Tecnologia do IFRS, v. 6, n. 1, p. 65 - 89, 2019.

SILVA, J. R. N.; ARENGHI, L. E. B.; LINO, A. Porque inserir física moderna e contemporânea no ensino médio? uma revisão das justificativas dos trabalhos acadêmicos. Revista Brasileira de Ensino de Ciência e Tecnologia, v. 6, n. 1, p. 69 - 83, 2013.

TIPLER, P. A.; LLEWELLYN, R. A. Física Moderna. 3. ed. Rio de Janeiro: LTC, 2006.

ZANOTTA, D. C.; CAPELLETO, E.; MATSUOKA, M. T. O gps: unindo ciência e tecnologia em aulas de física. Revista Brasileira de Ensino de Física, v. 33, n. 2, p. 2313, 2016. 